\title{
Structural local analysis and optimization of bus body skeleton
}

\author{
Lei Yang ${ }^{1,2, a}$, Song Deng ${ }^{1,2, \text { b* }}$ \\ ${ }^{1}$ Full address of second author, including country Hubei Key Laboratory of Advanced Technology \\ for Automotive Components, Wuhan University of Technology, Wuhan 430070, China \\ ${ }^{2}$ Hubei Collaborative Innovation Center for Automotive Components Technology, Wuhan University \\ of Technology, Wuhan 430070, China \\ a965816317@qq.com, bouoheng0722@126.com
}

\begin{abstract}
Keywords: Bus body skeleton, Cross-section shapes, Ends corner radius of roof crossrails, Local analysis and optimization

Abstract. It is very important to determine the specifications of components of vehicles at the initial design stage. Currently, the researches on torsional stiffness and weight optimization, structural improvement, and vibration and noise have been carried out. However, the structural local optimization of a component is ignored in the study of the bus body structure. To study the structural local analysis and optimization of the bus body skeleton, a numerical model of bus body skeleton was established using the Hyperworks software. Based on this simulated model of bus body skeleton, the thicknesses of the beams in the gussets, and the ends corner radius of the roof crossrails were varied to analyze their influences on the carrying capacity of the bus body skeleton. The results show that it is important to reasonable select the thicknesses of the beams, and the ends corner radius for the structural optimization and lightweight of the bus body skeleton.
\end{abstract}

\section{Introduction}

Previous work has been carried out on the structural optimization, lightweight and vibration and noise of the bus body skeleton. Many studies [1,2] mainly investigated the stress states of bus body skeleton under the conditions of the torsion, bend and the combination of bend and torison of the bus body, analyzed the carrying capacity, and optimized the body skeleton. The lightweight for the bus body skeleton was also studied based on the numerical and experimental methods [3,4], and the shape and size optimizations of parts of the body skeleton were implemented. The parameters iterative optimization of the bus body structure based on the sensitivity theory was carried out [5], and the bus body structure was available optimized. The vibration and noise of the bus body was also given attention. To reduce abnormal vibration and noise of a domestic bus, its finite element simulation and order tracking analysis of road test were performed, and the rotation angular frequencies of the wheels and two natural frequencies of the body structure were revealed to be overlapped[6, 7]. However, the studies above were primarily concentrated on the overall structure optimization of the bus body, the reduction of the overall weight, and the decline of vibration and noise, while little attention was paid to the theory of structural local analysis and optimizations, and the rule of the local stress state for the bus body skeleton. Therefore, it is of great importance to conduct the study on the structural local analysis and optimization of a bus body skeleton by developing an accurate simulated model of a bus body.

In this paper, a numerical model of the bus body skeleton was established using the Hyperworks software according to the modeling procedures[8-10]. Based on this simulated model of the bus body skeleton, the thicknesses of the beams in the gussets and the ends corner radius of the roof crossrails were varied to analyze their influences on the carrying capacity of the bus body skeleton. 


\section{Simulated model of bus body skeleton}

The body skeleton was meshed with quadrilateral elements, and the element size was $10 \mathrm{~mm}$. Beams were connected with the RBE2 elements to simulate the welds during the process of building the model. The material used in this simulated model was Q235B steel, and the main parameters are: Young's modulus $E=2.10 \times 105 \mathrm{MPa}$, Poisson's ratio $v=0.3$, material density $\rho `=7.85 \times 103 \mathrm{~kg} / \mathrm{m} 3$, tensile strength $\sigma_{t}=386 \mathrm{MPa}$. The thicknesses of beams were set according to the design drawing of the bus body skeleton. The numerical model of the body skeleton was shown in Fig. 1.

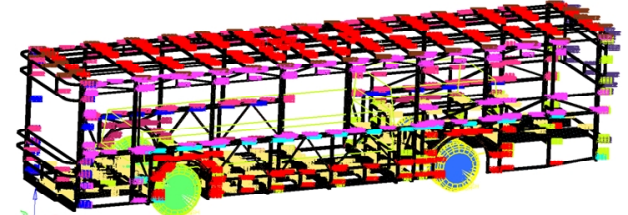

Fig. 1. Numerical model of bus body skeleton.

\section{Results and discussion}

The researched beams are called $\mathrm{zq}_{1}, \mathrm{zq}_{2}, \mathrm{zh}_{1}, \mathrm{zh}_{2}, \mathrm{zh}_{3}, \mathrm{yq}_{1}, \mathrm{yq}_{2}, \mathrm{yh}_{1}$, and $\mathrm{yh}_{2}$, and their thickness $t$ is $2.0 \mathrm{~mm}$, as shown in Fig. 2. The radius of the crossrail end corner is $70 \mathrm{~mm}$. To conduct the structural local analysis and optimization of the bus body skeleton, two distinct conditions are detailed below. Condition 1: To study the influence of the thickness of the researched beams on the stress states of gussets, the thickness is varied. $t=\{1.5,2.0,2.5,3.0\} \mathrm{mm}$ is selected. The other parameters stated in the original condition remain unchanged. Condition 2: To evaluate the effect of the radius of the crossrail end corner on the stress states of the gussets, the radius, $R^{`}=\{70,90,110,130,150\} \mathrm{mm}$, is selected, as described in Fig. 3. The other parameters stated in the original condition remain unchanged.
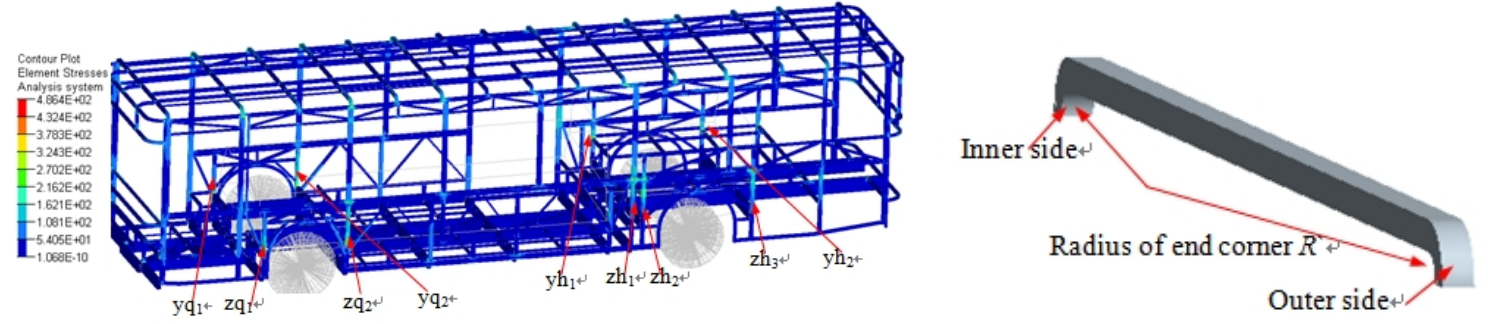

Fig. 2. Stress cloud of bus body skeleton. Fig.3. Position of crossrail end corner.

\section{Thicknesses of the researched beams}

Fig. 4 presents the maximum stress of the studied beams under various thicknesses. It can be seen that the maximum stress of the studied beams gradually decrease with increasing the thickness. This is because that the sectional area is increased with the increase of the thickness. Thus the moment of inertia of the cross-section shape is increased, which results in increasing the flexural rigidity. When the thickness $t$ is $1.5 \mathrm{~mm}$, the maximum stress of the studied beam is larger than the tensile strength, which suggests that the beams can't meet the demand of basic strength for the body skeleton. When the thickness $t$ is $3.0 \mathrm{~mm}$, the maximum stress of beams $\mathrm{yh}_{1}$ and $\mathrm{yh}_{2}$ is closer to that when the thickness is $2.5 \mathrm{~mm}$. This suggests that no obvious increase in the maximum stress of the beam occurs when the thickness is increased to certain value. Therefore, it is important to determine the sound thicknesses of the beams for increasing the stress strength and decreasing the weight of the bus body skeleton.

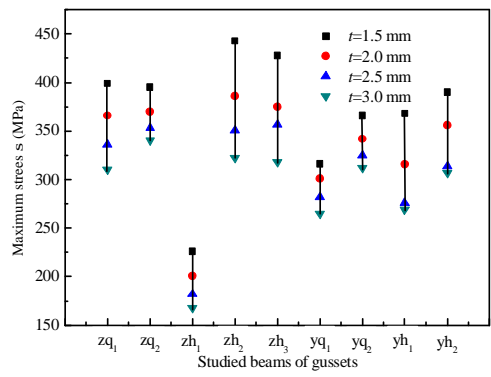

Fig. 4. Maximum stress of beam under various thicknesses. 


\section{Radius of the crossrail end corner}

Fig. 5 shows the maximum stress of the studied crossrail end under the various radius of the crossrail end corner. It can be seen that the maximum stresses of the studied crossrail ends on the outer and inner sides first decrease and then increase with the increase of radius $R$. This is because that the change of the radius $R^{`}$ induces the change of moment of the crossrail end. Fig. 6 shows the force condition of the crossrail end according to the theory of material mechanics. The increment of radius $R^{\prime}$ is named as $r^{\prime}$. The force exerted to the roof crossrail by the left gusset is marked as $F^{\wedge}$. The force analysis is conducted at the cross-section of angle $\varphi$ :

$$
\begin{aligned}
& N^{`}+F^{\prime} \sin \varphi^{`}=0, \\
& Q^{`}+F^{\prime} \cos \varphi^{`}=0, \\
& M^{`}=F^{\prime}\left(\left(R^{`}+r^{\prime}\right) \sin \varphi^{`}-\sqrt{r^{\prime 2}+2 R^{\prime} r^{\prime}}\right), \\
& \sigma_{b}=\frac{M\left(R_{b}-r_{b}\right)}{A_{b} r_{b}\left(r_{b}-R_{b}\right)}, \\
& R_{b}=\frac{A_{b}}{\int_{A_{b}} \frac{d A_{b}}{\eta}},
\end{aligned}
$$

where $N$ is the tensile force in the cross-section, $Q$ is the shearing force, $M$ is the moment of the cross-section, $\sigma_{\mathrm{b}}$ is the normal stress which is induced by $M R_{\mathrm{b}}$ is the distance between the curvature center of the roof crossrail and the neutral axis, $r_{\mathrm{b}}$ is the distance between the curvature center and $\sigma_{\mathrm{b}}$, $A_{\mathrm{b}}$ is the sectional area of the crossrail end, $r_{\mathrm{b}}$ is the distance between the curvature center and the centroid of the cross section, $\eta$ is the any place of the infinitesimal element $\mathrm{d} A_{\mathrm{b}}$. According to the Eqs. (1-5), it can be deduced that the pressure stress $\sigma_{\mathrm{n}}$ induced by $N$ and the shearing stress $\tau$ induced by $Q^{\prime}$ have no variation with increasing the radius of the crossrail end corner, and moment $M$ gradually increases with the increase of radius $R^{\prime}$. The stress $\sigma_{\mathrm{b}}$ is increased with the increase of $r_{\mathrm{b}}$ and $M$. When the radius $R^{`}$ is $70 \mathrm{~mm}$ ( $\varphi$ is very small at the moment), the crossrail end bears a small normal stress induced by the tensile force $N$. At the moment, the crossrail end main bears the normal stress $\sigma_{\mathrm{b}}$ and the shearing stress $\tau$. When the radius $R^{\prime}$ is $90 \mathrm{~mm}$ ( $\varphi^{\prime}$ is increased at the moment), the shearing stress $\tau$ is reduced, the normal stress $\sigma_{\mathrm{b}}$ is increased, and the pressure stress $\sigma_{\mathrm{n}}$ is increased. Thus, the equivalent stress at the crossrail end is reduced. When the radius continues to be increased $(\varphi$ is large at the moment), the increment of $\sigma_{\mathrm{b}}$ is larger than that $\sigma_{\mathrm{n}}$ so that the total normal stress is increased at the crossrail end. Moreover, when the radius $R^{\prime}$ is $150 \mathrm{~mm}$, the maximum stress at the crossrail end is nearly equivalent with that when the radius $R^{\prime}$ is $70 \mathrm{~mm}$. Therefore, the radius of the crossrail end corner has an important effect on the stress states of the crossrail end. The larger arc transition at the crossrail end is helpful to improve the carrying capacity of the bus body skeleton.
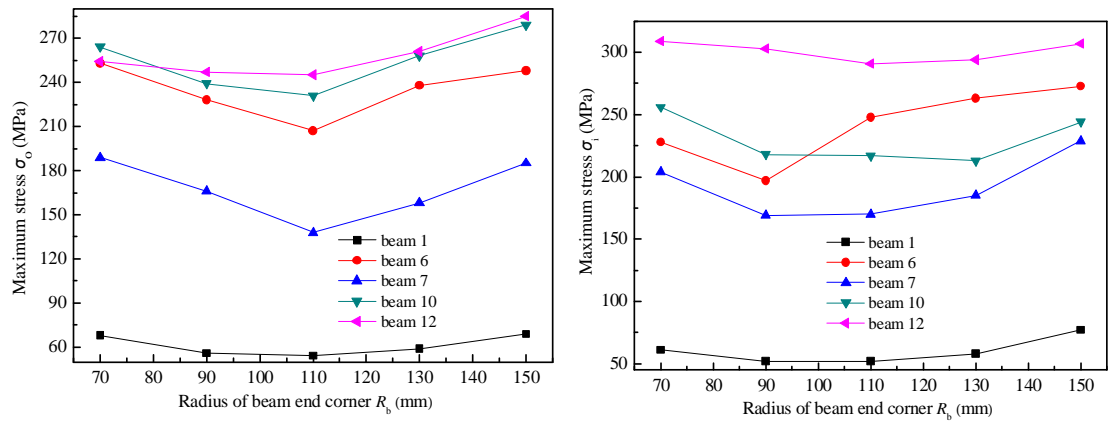

Fig. 5. Maximum stress of crossrail end corner: (a) stress of inner side, (b) stress of inner side. 


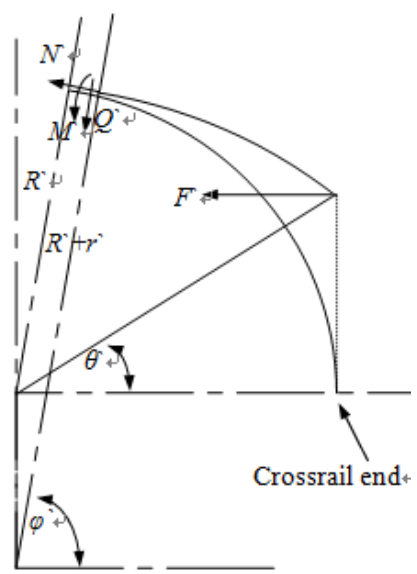

Fig. 6. Simplified diagram of force analysis for the crossrail end.

\section{Conclusions}

(1) It is important to determine the sound thicknesses of the beams for increasing the stress strength and decreasing the weight of the bus body skeleton. When the thickness $t$ is $1.5 \mathrm{~mm}$, the beams can 't meet the demand of basic strength for the body skeleton; When the thickness $t$ is $3.0 \mathrm{~mm}$, no obvious increase in the maximum stress of the beam occurs for beams $\mathrm{yh}_{1}$ and $\mathrm{yh}_{2}$.

(2) The radius of the crossrail end corner has an important effect on the stress states of the crossrail end. The larger arc transition at the crossrail end is helpful to improve the carrying capacity of the bus body skeleton.

\section{Acknowledgement}

The authors would like to thank the Innovative Research Team Development Program of Ministry of Education of China (No. IRT13087) and High-End Talent Leading Program of Hubei Province (No. 2012-86)for the support given to this research.

\section{References}

[1] Jiang FH, Fan YZ, Liu ET, et al. Finite Element Analysis of a Bus Skeleton and Structure Improvement. Advances in Intelligent Systems and Computing, 180(2013) 243-247.

[2] Gauchia A, Diaz V, Boada MJL, et al. Torsional stiffness and weight optimization of a real bus structure. International Journal of Automotive Technology, 11(2010) 41-47.

[3] Zhang XW, Tao Z. A study on shape optimization of bus body structure based on stiffness sensitivity analysis//10th International Conference on Computer-Aided Industrial Design and Conceptual Design, Wenzhou, China, November 26-29( 2009)1225-1229.

[4] Ding WQ, Tian C, Fan ZJ. Multi-objective optimization on the dynamic characteristics of bus structure based on surrogate model. Automotive Engineering, 34(2012)1072-1075+1093.

[5] Zheng RH, Han M, Wu XM. Bus Structural Optimization Based on Sensitivity Theory. International Conference on Electrical and Control Engineering, Wuhan, China, June 25-27(2010) 5076-5078.

[6] Wu GM, Shi WK, chen ZY, et al. Structural optimization of a light bus body-in-white based on modal sensitivity analysis. Journal of Vibration and Shock, 32(2013) 41-45.

[7] Wu GM, Shi WK, Liu W, et al. Optimization of bus body based on vehicle interior vibration. SAE Technical, DOI: 10.4271/2012-01-0221.

[8] Han XH, Hua L. Friction behaviors in cold rotary forging of 20CrMnTi alloy. Tribology International, 55(2012) 29-39.

[9] Han XH, Hua L. 3D FE modeling of cold rotary forging of a ring workpiece. Journal of Materials 
Processing Technology, 209(2009) 5353-5362.

[10] Han XH, Hua L, Zhuang WH, et al. Process design and control in cold rotary forging of non-rotary gear parts. Journal of Materials Processing Technology, 214(2014) 2402-2416. 